\title{
Spindle cells from AIDS-associated Kaposi's sarcoma lesions express telomerase activity that is enhanced by Kaposi's sarcoma progression factors
}

\author{
GIOVANNI BARILLARI ${ }^{1,2}$, ORNELLA FRANZESE ${ }^{1}$, ALESSANDRO COMANDINI ${ }^{1}$, \\ ENZO BONMASSAR ${ }^{1}$ and BARBARA ENSOLI ${ }^{2}$ \\ ${ }^{1}$ Departments of Experimental Medicine and Neuroscience, University 'Tor Vergata', 1 via Montpellier, 00133 Rome; \\ ${ }^{2}$ National AIDS Center, Istituto Superiore di Sanità, 299 viale Regina Elena, 00161 Rome, Italy
}

Received November 26, 2009; Accepted January 7, 2010

DOI: $10.3892 /$ or_00000849

\begin{abstract}
The activity of telomerase, a ribonucleoprotein maintaining the length of chromosome ends (telomeres) to levels allowing cells to replicate indefinitely, is undetectable in normal, differentiated cells, is present at low levels in some activated cell types (including endothelial cells) and it is highly expressed by tumor cells. Kaposi's sarcoma (KS), the most frequent tumor in Acquired Immune Deficiency Syndrome (AIDS) patients (AIDS-KS), arises as a disorder of new blood vessel formation (angiogenesis), but it may evolve into an aggressive cancer, characterized by the proliferation and invasion of spindle-shaped, endothelial-like cells (KS cells, KSC). Here we report that primary KSC express low telomerase levels which are strongly enhanced by $\mathrm{KS}$ initiation and progression factors including the inflammatory mediators interleukin (IL)-1ß, tumor necrosis factor (TNF) $\alpha$ and interferon (IFN) $\gamma$, the angiogenic basic fibroblast growth factor (bFGF) and the Tat protein of Human Immunodeficiency Virus (HIV)-1. Noteworthy, the increase of telomerase activity promoted by these molecules parallels the induction of KSC growth and invasion. These preliminary in vitro findings encourage measuring telomerase activity in AIDS-KS lesions in order to survey the clinical progression of the disease.
\end{abstract}

\section{Introduction}

Eukaryotic cell chromosomes end with special structures, termed telomeres, which consist of proteins and hundreds to thousands of tandem repeats of the sequence TTAGGG

Correspondence to: Dr Giovanni Barillari, Departments of Experimental Medicine and Neuroscience, University 'Tor Vergata', 1 via Montpellier, 00133 Rome, Italy

E-mail: barillar@uniroma2.it

Key words: Kaposi's sarcoma, telomerase, cell growth, cell invasion, cytokines, human immunodeficiency virus-1 Tat (reviewed in ref. 1). Telomeres are fundamental for the maintainance of chromosome integrity since in their absence chromosomes fuse, leading to unstable forms that can determine cell death (1).

In somatic cells telomere length progressively decreases with age in vivo and with cell division in vitro; when cells have reached a threshold minimal telomere length, they become uncapable of replicating and enter a non-dividing state termed cellular senescence (1).

In contrast, germline cells maintain telomere length to a level that allows them to escape from the replicative senescence and to proliferate indefinitely (reviewed in ref. 2). This is because these cells express the telomerase enzyme which, by adding TTAGGG sequences to the telomeres, compensates for the nucleotides lost during DNA replication $(1,2)$.

During cell differentiation telomerase activity decreases, and it is lost in most normal, mature somatic cells $(1,2)$. However, some normal cell types, including lymphocytes, epithelial and endothelial cells, express telomerase activity, which is tightly growth-regulated (3-5).

Telomerase is strongly reactivated in malignant cells and this is thought to contribute to their immortality (reviewed in ref. 6).

Indeed, following the development of the telomeric repetition amplification protocol (TRAP), a sensitive polymerase chain reaction (PCR)-based detection system (7), telomerase activity has been detected in a wide variety of tumors $(2,6)$. Tumor tissues, but not normal tissue adjacent to the tumor, express telomerase activity in a fashion which directly correlates with the percentage of cycling cells $(2,6)$.

Telomerase is also detectable in cells from pre-neoplastic lesions, thus suggesting that the enzyme is activated since early stages of carcinogenesis $(8,9)$.

In this regard, KS, a vascular tumor frequently developing in HIV-1-infected individuals (AIDS-KS) (reviewed in ref. 10), does not arise as a true malignancy but rather as an inflammatory-proliferative disorder. Specifically, early AIDS-KS lesions resemble a granulation tissue, as they are infiltrated by activated lymphocytes and macrophages, mixed with fibroblasts and proliferating endothelial cells (10). Later, spindle-shaped, endothelial-like cells of polyclonal nature (KSC) appear in the lesions, being their 
histologic hallmark (10). With time, KSC increase their growth rate, become monoclonal, and invade the skin, lymph nodes and viscera, thus leading to AIDS-KS progression into an aggressive malignant tumor (10).

Previous studies indicated that inflammatory mediators, angiogenic factors, the HIV-1 Tat protein and the human herpesvirus 8 (HHV8) cooperate in AIDS-KS initiation and progression (10).

In particular, the inflammatory cytokines IL- $1 \beta, T N F \alpha$ and IFN $\gamma$, which are increased in blood and tissues of individuals with $\mathrm{KS}$ or at risk of $\mathrm{KS}$, can both reactivate HHV 8 infection and induce normal endothelial cells to acquire KSC phenotype (10). The latter includes the spindle shape, the expression of endothelial cell activation markers, and the capability of promoting the development of angioproliferative, KS-like lesions in nude mice (10). These events are due to the fact that inflammatory cytokines induce the synthesis and release of bFGF, an angiogenic molecule highly expressed in KS lesions (10). bFGF is pivotal for KS onset since it promotes angiogenesis and KSC growth, migration and invasion (10).

Inflammatory cytokines and bFGF are expressed in all forms of KS (10). However, KS is much more frequent and aggressive in AIDS patients (10). This appears to be due to the Tat protein of HIV-1, a transactivator of viral gene expression which, upon its release by acutely infected cells, promotes KSC proliferation and invasion and synergizes with bFGF in inducing angiogenesis (reviewed in ref. 11).

Results from a previous study indicate that telomerase activity is detectable in AIDS-KS biopsies (12). However, that study did not correlate the intensity of telomerase activity with the presence of KS initiation or progression factors, nor did it address whether KSC, among the various cell types composing the $\mathrm{KS}$ lesions, express telomerase activity (12).

Therefore, we assessed whether primary KSC express telomerase activity and, then, we evaluated whether this was modulated by molecules present in AIDS-KS lesions, and playing a role in the development and progression of the disease.

\section{Materials and methods}

Reagents. Human recombinant bFGF, IL-1ß, TNF $\alpha$ and IFN $\gamma$ were purchased from Roche Molecular Biochemicals (Indianapolis, IN, USA). Recombinant Tat protein (from the HIV-1 IIIB isolate) was expressed, purified, tested for biological activity, and handled as reported elsewhere (13).

Cell cultures. Primary KSC cultures were established from a skin lesion of a 32-year-old male AIDS-KS patient, as previously described (14). Immune staining indicated that KSC expressed markers of activated endothelial cells of either vascular or lymphatic origin, including CD31, UEA, VEcadherin, ICAM-1, D2-40 and LYVE-1 (15). In addition, the cells displayed macrophage antigens such as CD68, CD14, and PAM-1 (16). These findings are in agreement with a previous study (11) and they confirm that KSC are likely to derive from the so-called endothelial macrophages of lymph node sinuses (17). Cells showed a limited life-span (reaching
20 passages maximum) and were found to be negative for HIV-1 or HHV8 infection by PCR.

Primary vascular smooth muscle cells (VSMC) from the human aorta arteria were obtained from Lonza (Verviers, Belgium). The EA.hy 926 cell line, derived by fusing human endothelial cells with human lung carcinoma cells (18), was from American Type Culture Collection (Rockville, MD, USA).

Determination of telomerase activity. Telomerase activity was assayed in KSC, VSMC, or EA.hy 926 cell extracts, according to the TRAP method (7). Briefly, cells $\left(1 \times 10^{6}\right)$ were washed in phosphate-buffered saline (PBS) solution, and lysed in ice-cold extraction buffer containing $0.5 \%$ 3 [(cholamido-propyl)-dimethyl-ammono]-1-propanesulfonate, $10 \mathrm{mM}$ Tris- $\mathrm{HCl}(\mathrm{pH} 7.5), 1 \mathrm{mM} \mathrm{MgCl}_{2}, 1 \mathrm{mM}$ EGTA, 5 mM ß-mercaptoethanol, $0.1 \mathrm{mM}$ [4(2-aminoethyl)benzene-sulfonyl fluoride] hydrochloride and $10 \%$ glycerol. Total proteins $(0.5 \mu \mathrm{g})$ were dissolved in $50 \mu \mathrm{l}$ of a reaction mixture containg $20 \mathrm{mM}$ Tris- $\mathrm{HCl}(\mathrm{pH} 8.3), 68 \mathrm{mM} \mathrm{KCl}$, $1.5 \mathrm{mM} \mathrm{MgCl}_{2}, 1 \mathrm{mM}$ EGTA, $0.05 \%$ Tween-20, $0.1 \mu \mathrm{g}$ of the primer TS (5'-AATCCGTCGAGCAGAGTT), $0.5 \mathrm{mM}$ T4 gene 32 protein, $10 \mathrm{mM}$ deoxynucleotide triphosphate, 2 units of Taq polymerase (Promega, Madison, WI, USA) and $2 \mu \mathrm{Ci}$ of $\left[\alpha-{ }^{32} \mathrm{P}\right]-\mathrm{dCTP}(3,000 \mathrm{CI} / \mathrm{mmol}$, DuPont NEN Research Products, Boston, MA, USA). Each reaction was carried out in a PCR tube containing $100 \mathrm{ng}$ of the oligonucleotide 5'-(CCCTTTA) ${ }_{3}$ CCCTAA (Biogen, Rome, Italy). Samples were incubated at $22^{\circ} \mathrm{C}$ for $20 \mathrm{~min}$ to allow telomerase to extend TS primer, followed by a 31-cycle PCR amplification of the telomeric products. The PCR products (40 $\mu \mathrm{l})$ were run onto $10 \%$ non-denaturing acrylamide gels. Gels were fixed in $0.5 \mathrm{M} \mathrm{NaCl}, 50 \%$ ethanol and $40 \mathrm{mM}$ sodium acetate ( $\mathrm{pH} 4.2)$ and then exposed to X-ray film (Kodak, Rochester, NY, USA) at $-80^{\circ} \mathrm{C}$. Band intensity was quantified by bidimensional densitometry of the first eight ladder bands, using a Bio-Rad (Richmond, CA) scanning system (Imaging Densitometer GS-670, Molecular Analyst Software). The signal intensity of each band was measured and corrected for the background levels. The adjusted signals of the ladder products in each lane, expressed in optical density units, were summed and used for quantitative analysis.

Cell growth and invasion assays. Cell growth assays were performed with KSC exposed or not to recombinant IL-1ß, TNF $\alpha$ and IFN $\gamma$ combined, bFGF or Tat in RPMI-1640 medium containing $10 \%$ foetal bovine serum (Invitrogen Italy, Milan, Italy). Media and proteins were replaced after 2 days, and cells were counted after 4 days by trypan blue dye exclusion (in triplicate), as previously described (19).

Invasion assays were performed in modified Boyden chambers separated in two compartments by polycarbonate filters coated with Matrigel ${ }^{\mathrm{TM}}$ (Becton-Dickinson Biosciences Italy, Buccinasco, Italy), a reconstituted basement membrane which prevents migration of non-invasive cells (19). KSC were incubated for 5 days with IL-1B, TNF $\alpha$ and IFN $\gamma$ combined, bFGF, Tat or medium alone, suspended by trypsinization, washed with trypsin inhibitors and then placed in the upper compartment of the Boyden chamber. Serum- 
free medium was placed in the lower compartment. Invaded cells were fixed in ethanol, double stained by toluidine-blue and by hematoxylin- eosin, and quantitated by light microscopy by counting 5 fields/ filter, as described (19).

\section{Results}

Initial experiments measured telomerase activity in primary KSC kept under basal culture conditions. For this purpose we employed the TRAP method, which shows the presence of telomerase activity in cellular extracts by a ladder of PCR products differing in size by the addition of TTAGGG repeats (7). Quiescent VSMC were employed as the negative control (20), while the EA.hy 926 cell line was the positive control (18).

Results indicated that quiescent VSMC were telomerasenegative (Fig. 1), in agreement with previous studies (20). In contrast, primary KSC expressed telomerase activity, albeit to a low level as compared to the EA.hy 926 cell line (Fig. 1).

However, when KSC were exposed to KS progression factors including IL-1 $\beta, \mathrm{TNF} \alpha$, IFN $\gamma, \mathrm{bFGF}$ and/or Tat, at concentrations likely to be present in vivo $(10,11)$, telomerase activity was enhanced, starting at $48 \mathrm{~h}$ of treatment. Prolonged exposure (5 days) to cytokines or Tat further increased KSC telomerase activity, which reached levels similar to those detected in the EA.hy 926 tumor endothelial cells. Specifically, at 5 days, combined IL-1ß, TNF $\alpha$ and IFN $\gamma$ augmented KSC telomerase activity by 2.96 -fold over basal levels (Fig. 1). Consistent with their key role in KS pathogenesis, also bFGF and Tat enhanced KSC telomerase activity by 2.53 - and 1.59-fold, respectively, over basal levels (Fig. 1).

Additional experiments were performed to assess whether there was any link between telomerase activity and KSC growth rate or invasiveness.

Results indicate that the increase in telomerase activity was simultaneous with the induction of KSC proliferation by IL-1 1, TNF $\alpha$ and IFN $\gamma$ combined, bFGF or Tat (Fig. 2A). Combined inflammatory cytokines, bFGF or Tat also increased KSC invasion by 3.1-fold, 2.63-fold and 1.5-fold, respectively (Fig. 2B).

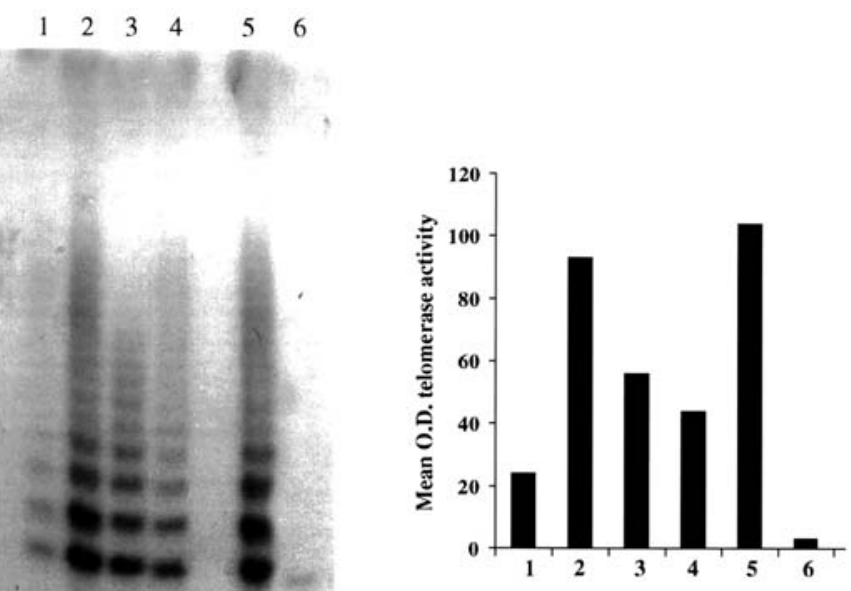

Figure 1. KSC express telomerase activity which is increased by combined inflammatory cytokines, bFGF or HIV-1 Tat. Telomerase activity was measured in KSC cultured in the absence (lane 1) or presence of recombinant IL- $1 \beta, T N F \alpha$ and IFN $\gamma$ combined together at $10,0.5$ and $0.15 \mathrm{ng} / \mathrm{ml}$, respectively (lane 2), $20 \mathrm{ng} / \mathrm{ml}$ of bFGF (lane 3), or $20 \mathrm{ng} / \mathrm{ml}$ of Tat (lane 4). The EA.hy 926 cell line was employed as the positive control (lane 5), while VSMC grown in $1 \%$ FBS were the negative control (lane 6). The autoradiography (left panel) and its densitometric analysis (right panel) from a representative experiment out of three performed are shown. Fold increase of KSC telomerase activity induced by Tat or cytokines are reported in text (where values refer to the three performed experiments).

\section{Discussion}

Differently from the majority of normal, differentiated cells, and similarly to germline cells, tumor cells express telomerase activity $(1,2,6)$. Noteworthy, the intensity of telomerase activity in tumor specimens directly relates to tumor cell growth and invasiveness, thus parallelling, at least in certain tumor types, the different stages of cancer progression $(2,6,9,21,22)$. In addition, telomerase appears to distinguish benign hyperplasia from cancer $(23,24)$.
A

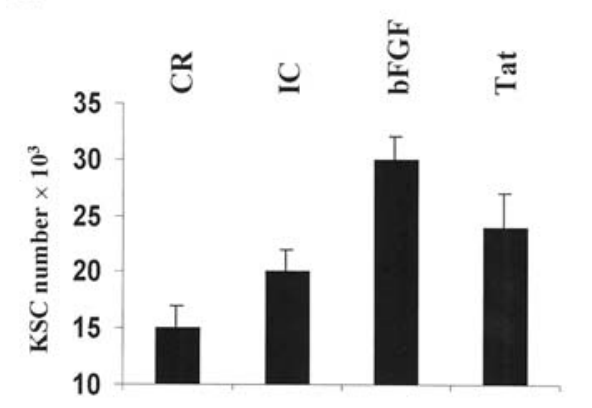

B

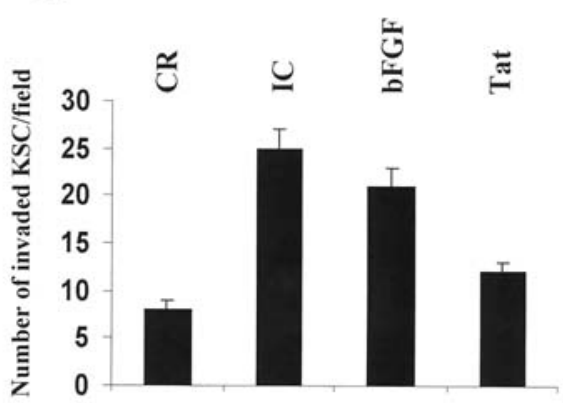

Figure 2. KS promoting factors which upregulate KSC telomerase activity also stimulate the proliferation and invasion of these cell types. KSC were grown for 5 days in the absence (CR) or in the presence of the recombinant inflammatory cytokines (IC) IL-1B, TNF $\alpha$ and IFN $\gamma$ (combined together at $10,0.5$ and $0.15 \mathrm{ng} / \mathrm{ml}$, respectively), bFGF (20 ng/ml) or Tat $(20 \mathrm{ng} / \mathrm{ml})$. (A) Data are expressed as the average number of KSC after $5 \mathrm{days}$ of culture from 3 experiments each performed in duplicate wells $( \pm \mathrm{SD})$. (B) Results are expressed as the number of invaded cells/field from 3 experiments each performed in duplicate chambers $( \pm \mathrm{SD})$. 
Previous studies indicated that active telomerase is present in lesions from AIDS-KS (12), an angioproliferative disease which can evolve into an aggressive sarcoma (10).

Here we have shown that KSC, the histologic hallmark of KS lesions (10), constitutively express low telomerase levels, and that these are strongly enhanced by IL-1B, TNF $\alpha, \operatorname{IFN} \gamma$, bFGF or HIV-1 Tat, reaching the levels expressed by a tumor cell line. Of note, we also observed that the increase of telomerase activity promoted in primary KSC by the above mentioned KS initiation/progression factors parallels KSC replicative index and invasiveness. In particular, we found that the enhancement of KSC telomerase activity induced by bFGF or Tat correlates with an increase in both KSC growth and invasiveness. In contrast, while combined IL-1ß, TNF $\alpha$ and IFN $\gamma$ are particularly effective at enhancing $\mathrm{KSC}$ telomerase expression and invasiveness, they promote $\mathrm{KSC}$ growth to a lesser degree. This is consistent with the fact that inflammatory cytokines increase the growth rate of KSC indirectly, either by augmenting KSC adhesive properties, or by stimulating KSC to synthesize bFGF which, in turn, acts as an autocrine KSC growth factor (10). Notwithstanding, the enhancement of KSC telomerase activity and invasiveness by IL-1 13, TNF $\alpha$ and IFN $\gamma$ is biologically relevant, as these cytokines promote $\mathrm{KS}$ onset or progression in humans $(25,26)$.

Altogether, these findings are in agreement with the fact that the intensity of telomerase activity in tumors correlates with tumor cell growth rate, and that telomerase-expressing tumor cells invade the basement membrane, while telomerasenegative cells do not $(2,6,22,27)$.

The detection of telomerase activity in KSC is somehow surprising since those cells are not tranformed nor tumorigenic. In particular, KSC are contact-inhibited and have a limited life-span (10). In addition, it has to be highlighted that, although $\mathrm{KSC}$ injection in nude mice promotes the development of angioproliferative, KS-like lesions, these are of mouse cell origin, being induced by the paracrine action of cytokines and angiogenic factors produced by KSC (10). Indeed, evidence suggests that KSC are likely to be 'transdifferentiated' rather than transformed cells. In fact, KSC express antigens which are typical of macrophage, endothelial cell precursors, vascular endothelial cells or lymphatic endothelial cells $(10,17)$. Moreover, KSC show peculiar functional traits. Specifically, they proliferate in response to combined IL-1ß, TNF $\alpha$ and IFN $\gamma$ (Fig. 2A), while these same cytokines inhibit the growth of endothelial cells or even cause their apoptosis (28). Similarly, extracellular matrix fragments promote $\mathrm{KSC}$, but not endothelial cell growth (19), hence indicating that KSC possess an altered intracellular signaling through the integrin receptors. Again differently from normal endothelial cells, KSC are not sensitive to the mitogenic effect of vascular endothelial growth factor, although they express the receptors for this angiogenic cytokine $(10,11)$. Finally, KSC, but not endothelial cells, are characterized by the constitutive activation of matrix metalloproteases, which mediate KSC invasive properties (10).

In this regard, also the low levels of basal telomerase activity we detected in primary KSC suggest that they are activated cells rather than true tumor cells. Nevertheless, the finding that well-established KS initiation/progression factors enhance KSC telomerase activity, and that this is accompanied by an increase in KSC growth rate and invasiveness, makes telomerase a good candidate to monitor AIDS-KS clinical progression.

Longitudinal studies will be needed to determine if telomerase levels in AIDS-KS biopsies can distinguish the different stages of disease progression. In vivo studies should also evaluate whether in KS patients telomerase activity correlates with response to therapy.

\section{Acknowledgements}

This study was supported by grants from the Italian Ministry of Health, National AIDS Program (to G.B.) and the Italian Association for Cancer Research (to B.E.).

\section{References}

1. Blackburn EH: Telomeres and telomerase: their mechanisms of action and the effects of altering their functions. FEBS Lett 579: 859-862, 2005.

2. Aubert G and Landsdorp PM: Telomeres and aging. Physiol Rev 88: 557-579, 2008.

3. Kaszubowska L: Telomere shortening and ageing of the immune system. J Physiol Pharmacol 59: 169-186, 2008.

4. Krunic D, Moshir S, Greulich-Bode KM, Figueroa R, Cerezo A, Stammer H, Stark HJ, Gray SG, Nielsen KV, Hartschuh W and Boukamp P: Tissue context-activated telomerase in human epidermis correlates with little age-dependent telomere loss. Biochem Biophys Acta 1792: 297-308, 2009.

5. Kurz DJ, Hong Y, Trivier E, Huang HL, Decary S, Zang GH, Luscher TF and Erusalimsky JD: Fibroblast growth factor-2, but not vascular endothelial growth factor, upregulates telomerase activity in human endothelial cells. Arterioscl Thromb Vasc Biol 23: 748-754, 2003.

6. Shay JW and Roninson IB: Hallmarks of senescence in carcinogenesis and cancer therapy. Oncogene 23: 2919-2933, 2004.

7. Piatyszek MA, Kim NW, Weinrich SL, Hiyama K, Wright WE and Shay JW: Detection of telomerase activity in human cells and tumors by a telomeric repeat amplification protocol. Methods Cell Sci 17: 1-15, 1995.

8. Wisman GB, De Jong S, Meersma GJ, Helder MN, Hollema H, de Vries EG, Keith WN and van der Zee AG: Telomerase in (pre)neoplastic cervical disease. Hum Pathol 31: 1304-1312, 2000.

9. Sharma A, Rajappa M, Saxena A and Sharma M: Telomerase activity as a tumor marker in Indian women with cervical intraepithelial neoplasia and cervical cancer. Mol Diagn Ther 11: 193-201, 2007.

10. Ensoli B, Sgadari C, Barillari G, Sirianni MC, Sturzl M and Monini P: Biology of Kaposi's sarcoma. Eur J of Cancer 37: 1251-1269, 2001.

11. Barillari G and Ensoli B: Role of HIV-1 Tat protein in the pathogenesis of AIDS-associated Kaposi's sarcoma. Clin Microbiol Rev 15: 310-326, 2002.

12. Chen Z, Smith KJ, Skelton HG, Barret TL, Greenway HT and Lo SC: Telomerase activity in Kaposi's sarcoma, squamous cell carcinoma, and basal cell carcinoma. Exp Biol Med 226: 753-757, 2001.

13. Fanales-Belasio E, Moretti S, Fiorelli V, Tripiciano A, Pavone-Cossut MR, Scoglio A, Colacchi B, Nappi F, Macchia I, Bellino S, Francavilla V, Caputo A, Barillari G, Magnani M, Laguardia ME, Cafaro A, Titti F, Monini P, Ensoli F and Ensoli B: HIV-1 Tat addresses dendritic cells to induce a predominant Th1-type adaptive immune response that appears prevalent in the asymptomatic stage of infection. J Immunol 182: 2888-2897, 2009.

14. Ensoli B, Nakamura S, Salahuddin SZ, Biberfeld P, Larsson L, Beaver B, Wong-Staal F and Gallo RC: AIDS-Kaposi's sarcomaderived cells express cytokines with autocrine and paracrine growth effects. Science 243: 223-226, 1989.

15. Rocha SF and Adams RH: Molecular differentiation and specialization of vascular beds. Angiogenesis 12: 139-147, 2009. 
16. Hume DA: Differentiation and heterogeneity in the mononuclear phagocyte system. Mucosal Immunol 1: 432-441, 2008.

17. Kaaya EE, Castanos-Velez E, Amir H, Lema L, Luande J, Kitinya J, Patarroy $M$ and Biberfeld P: Expression of adhesion molecules in endemic and epidemic Kaposi's sarcoma. Histopathology 29: 337-346, 1996.

18. Lu ZY, Jensen LE, Huang Y, Kealey C, Blair IA and Whitehead AS: The up-regulation of monocyte chemoattactant protein-1 (MCP-1) in Ea.hy 926 endothelial cells under longterm low folate stress is mediated by the p38 MAPK pathway. Atherosclerosis 205: 48-54, 2009.

19. Barillari G, Sgadari S, Fiorelli V, Samaniego F, Colombini S, Manzari V, Modesti A, Nair BC, Cafaro A, Sturzl M and Ensoli B: The Tat protein of human immunodeficiency virus type- 1 promotes vascular cell growth and locomotion by engaging the $\alpha 5 \beta 1$ and $\alpha v \beta 3$ integrins and by mobilizing sequestered basic fibroblast growth factor. Blood 94: 663-672, 1999.

20. Ogawa D, Nomiyama T, Nakamachi T, Heywood EB, Stone JF, Berger JP, Law RE and Bruemmer D: Activation of peroxisome proliferator-activated receptor gamma suppresses telomerase activity in vascular smooth muscle cells. Circ Res 98: e50-e59, 2006.

21. Zhang DK, Ngan HY, Cheng RY, Cheung AN, Liu SS and Tsao SW: Clinical significance of telomerase activation and telomeric restriction fragment (TFR) in cervical cancer. Eur J Cancer 35: 154-160, 1999.
22. Dorer DE and Nettelbeck DM: Targeting cancer by transcriptional control in cancer gene therapy and viral oncolysis. Adv Drug Deliv Rev 61: 554-571, 2009.

23. Botchkina GI, Kim RH, Botchkina IL, Kirshembaum A, Frisher Z and Adler HL: Noninvasive detection of prostate cancer by quantitative analysis of telomerase activity. Clin Cancer Res 11: 3243-3249, 2005.

24. Onoda N, Ogisawa K, Ishikawa T, Takenaka C, Tahara H, Inaba M, Takashima $\mathrm{T}$ and Hirakawa K: Telomerase activation and expression of its catalytic subunits in benign and malignant tumors of the parathyroid. Surg Today 34: 389-393, 2004.

25. Aboulafia DS, Miles SA, Saks SR and Mitsuyasu RT: Intravenous recombinant tumor necrosis factor in the treatment of AIDS-related Kaposi's sarcoma. J Acquir Immune Defic Syndr 2: 54-58, 1989.

26. Albrecht H, Stellbrink HJ, Gross G, Berg B, Helmchen V and Mensing H: Treatment of atypical leishmaniosis with interferongamma resulting in progression of Kaposi's sarcoma in an AIDS patients. Clin Invest 72: 1041-1047, 1994.

27. Shariftabrizi A, Khorramizadeh MR, Saadat F, Alimoghadam K, Safavifar F and Ebrahimkhani MR: Concomitant reduction of matrix metalloproteinase-2 secretion and intracellular reactive oxygen species following anti-sense inhibition of telomerase activity in PC-3 prostate carcinoma cells. Mol Cell Biochem 273: 109-116, 2005.

28. Savage CO: Vascular biology and vasculitis. APMIS (Suppl) 127: 37-40, 2009. 